\title{
PEREIRA, Elvya Ribeiro. Piguara: Alencar e a invenção do Brasil. Feira de Santana: Editora UEFS, 2000.
}

\author{
Maria Theresa Abelha Alves \\ Universidade Federal do Rio de Janeiro \\ Universidade Estadual de Feira de Santana
}

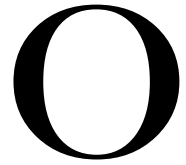

Programa de Pósgraduação em Literatura e Diversidade Cultural vem publicando, regularmente, ensaios de interesse dos que se dedicam aos estudos literários. Tanto professores e alunos de cursos de Letras quanto os demais interessados nos fatos culturais constituem o público-alvo destas edições. Um dos títulos da coleção, Piguara: Alencar e a invenção do Brasil, vem ocupar um lugar de destaque no acervo crítico do grande romântico brasileiro. Sua autora, de início, jogando com a biografia de Alencar e suas obras críticas e literárias, com propriedade recupera o pensamento exposto na última carta sobre a Confederação dos Tamoios (quando o romancista troçara do personagem Brás Cubas, do poema de
Gonçalves de Magalhães) e o expresso em Como e porque sou romancista (quando expusera seu desejo de se tornar "escritor póstumo") e resgata, assim, o diálogo (duelo?) entre Alencar e Magalhães, ensejando um multílogo de que fazem parte os dois escritores nomeados e outros que compunham o cenário literário e crítico do século XIX. Desse processo não escapam a ensaísta e seus leitores, que são convocados a desenvolverem novas habilidades de leitura, e, obviamente, Machado de Assis que é convidado especial na obra que celebra Alencar, pois o concerto de vozes é mediatizado pela figura emblemática de Brás Cubas. Ficção de ficção, numa linha tão cara ao pós-modernismo? Não. Apenas um lúcido e bem urdido questionamento 
acerca do papel pioneiro de Alencar no pensar o Brasil e no querer inventá-lo autenticamente genuíno.

Numa série de oito capítulos, nomeados todos com humor e ironia, mas sempre com muita pertinência, entre as "Memórias Póstumas" e as "Memórias Prósperas", o livro se desenvolve como um convite à emoção compartilhada. A partir mesmo dos títulos atribuídos a cada capítulo, o leitor percebe que sua leitura do ensaio tem que trilhar as vias transversas trilhadas por Elvya em sua leitura de Alencar. Em geral, a crítica alencariana e a crítica sobre o Romantismo brasileiro percorreram as mesmas sendas. A leitura de Elvya encontra os críticos da obra de Alencar e deles faz uma criativa leitura que não os repete, mas os tensiona. Se repetição há, ela se dá na diferença. Os caminhos se entrecruzam, mas a caminhada é outra, ousando não só descolorir em sépia o retrato ideológico tradicionalmente conferido a José de Alencar, como também pintá-lo em cores vivas. É este o desafio que o ensaio lança a seus leitores, eles também têm que abandonar suas bases de análise e lançar-se ao novo. Como a de Dante, guiada por Virgílio, a caminhada que se espera dos leitores não constitui tarefa difícil, pois eles têm a guiá-los uma autora, antes leitora apaixonada de Alencar, que, numa linguagem correta, e mediante uma notável bibliografia (quantitativa e qualitativamente), investiga o século XIX e suas correntes criativas, ideológicas e estéticas. Assim, Elvya conduz seus interlocutores à reflexão, através de socrático método em que respostas não são dadas, mas perguntas são propostas para fomentarem o olhar por outras perspectivas.

O primeiro capítulo "Memórias Póstumas" - inicia, como ocorre no romance de Machado de Assis, com a narração da morte do herói. O dado biográfico e factual lá está: dia e hora do desenlace. O fato, que teve uma repercussão modesta na cena carioca, levou o Imperador a dizer, laconicamente: "Homem inteligente... mas muito malcriado". A ensaísta se apropria deste episódio para, a partir dele, perscrutar o tom, a atmosfera, a mentalidade novecentista. É com a história das 
mentalidades que contextualiza a época de José de Alencar, fornecendo o quadro referencial ideológico, estético e retórico que circunscreveu o escritor e condicionou-lhe a pena. Ao apresentar uma citação de Paul Veyne como epígrafe o ensaio delineia sua não inocência. A mentalidade do tempo em que Alencar viveu é responsável pelo incontornável embate de forças contraditórias que as obras de criação e de crítica do romancista cearense ilustram, ao apresentarem o ideal do homem civilizado e os confrontos traumáticos da colonização sob o véu poético de uma natureza paradisíaca e harmonizadora. A mentalidade do tempo justifica a construção da pátria brasileira neste "entre-lugar": natureza e cultura.

O segundo capítulo "Comentário virtual: 'é a cara do pai'" - trabalha a relação paifilho, tal como se expressa pelo imaginário romântico brasileiro, observando ora os paratextos alencarianos, ora seus romances indianistas com a finalidade de refletir sobre a problemática subjacente à metáfora familiar, ou seja, a tensão entre o "instinto de nacionalidade" e o fantasma obsidiante da "matriz cultural".

O terceiro capítulo - "Piguara - o criador e a criatura" - fornece ao leitor a chave para a compreensão do título geral da obra, ao expor a tradução dada pelo autor de O Guaranià palavra indígena "piguara": guia, senhor dos caminhos. Porém não é de qualquer caminho que se trata, mas daquelas veredas que se fazem sob os pés dos primeiros andarilhos. A partir do prefácio a Sonbos d'Ouro, a ensaísta, à luz do significado de "piguara", pondera que tal vocábulo, de certa maneira, poderia ser atribuído ao próprio Alencar que, por sua atividade romanesca e crítica, abriu caminhos e deles se fez senhor no que concerne a um projeto de fundação de uma cultura brasileira. É o pioneirismo de Alencar que justifica o deslocamento temporal que se verifica em sua obra indianista e que objetivava atenuar o atrito das culturas (a précabralina autóctone e a européia civilizacional), mediante o deslizar e a indefinição entre o mito e a história.

O quarto capítulo - "A santíssima trindade indianista" - discu- 
te os três romances de fundação da identidade nacional. Revisitando a literatura de viagens que fora objeto de leitura de Alencar para a configuração do problema indígena, Elvya desvela a armadilha que o "europeocentrismo romântico" armou para Alencar e em que ele caiu, quando tomou de empréstimo os valores dos colonizadores para tecer o perfil de seus heróis indígenas. A autora revela as ambigüidades do romancista, suas opções políticas conservadoras sem deixar de registrar seus avanços estéticos. Analisando Ubirajara, demonstra o caráter de pureza étnica que foi conferido ao herói fundador da nação tabajara, pois o romance recua para o período pré-cabralino, a fim de criar um índio diferente daquele que aparecia nos relatos dos cronistas e viajantes. Elvya mostra como esse novo retrato se pinta com as cores dos grandes heróis ocidentais, tais como os consagrados pelas epopéias homéricas ou pelos romances medievais, quando investiga a trilha de glória que se molda pelo binômio caçador/guerreiro, inscrito nos nomes que o herói adquire na diegese: Jaguaré e Ubirajara. Analisando O Guarani, a estudiosa focaliza dois momentos cruciais para a economia do romance: o início em que se evidenciam as contradições inerentes a um tempo dividido entre a ética senhorial e a prática do capitalismo emergente, e o final, quando o "dilúvio" faz Peri recontar a lenda de Tamandaré - o herói indígena que, qual Noé, sobreviveu à enchente para iniciar uma nova era - que acentua o esgarçamento de limites, comum aos romances indianistas alencarianos, entre o real e o fantástico, a história e o mito. Analisando Iracema, ilumina o símile natureza-mãe que o romance, por meio da protagonista, instaura. A simbiose natureza-Iracema a um só tempo metaforiza o projeto de uma literatura americana e neutraliza o processo mortífero da colonização, pois se Iracema sucumbe, a natureza (seu símile e símile da raça americana) irrompe viçosa e pujante, como a insinuar que, a despeito do que for, manterse-á viva.

No quinto capítulo - "Diálogos Brasil: Alencar, Freyre e a identidade brasileira" -, com a 
astúcia de grande investigador, Elvya "garimpa" na obra de Gilberto Freyre elementos retóricos, estéticos e ideológicos que traduzem um possível diálogo entre o pensador pernambucano e o escritor cearence, tanto na pretensão de usar uma língua com sabor e sensualidade tropicais, quanto no cultivo da polêmica, quanto no exercício de um diálogo com os leitores através de paratextos explicativos dos respectivos projetos de construção de uma identidade nacional. Mediante a reflexão sobre os escritos de um e outro, faz-se a análise do Romantismo e também passa-se a limpo as propostas Modernistas dos grupos de São Paulo e de Recife. Questões cruciais para um e outro movimento, como a oralidade, o uso de coloquialismos e o emprego dos pronomes pessoais, são retomadas e esclarecidas.

O sexto capítulo - "Um leitor de Alencar" - reflete sobre a atividade de Brito Broca, sem dúvida um dos mais perspicazes críticos da obra de José de Alencar na década de cinqüenta do século passado. Teorizando sobre o crítico, a ensaísta observa o quão importante é a contextualização espácio-temporal, pois sem ela se perderiam importantes referências retóricas e ideológicas que inserem a produção alencariana no concerto das idéias e das forças sociais que dinamizaram as polêmicas literárias de que Alencar participou. Para ilustrar, são contextualizadas duas delas: a questão da linguagem brasileira que colocou em campos opostos José de Alencar, José Feliciano de Castilho e Franklin Távora e aquela em que se bateram Alencar e Joaquim Nabuco.

No sétimo capítulo, intitulado, com muita originalidade, "Do alto da Boa Vista à Garnier", são focalizadas as cartas trocadas (e abertas ao público nos jornais da época) entre o autor de Iracema e Machado de Assis, sobre o jovem poeta Castro Alves. Com inegável e invejável argúcia crítica, são lidos, nas entrelinhas e nos interditos, os aspectos problemáticos que envolviam a literatura do século XIX, e que podem ser metaforizados no movimento da "natureza" para a "civilização", isto é, do Alto da Boa Vista para a livraria Garnier. Assim, o livro de Elvya estabelece uma 
peregrinatio ad loca literae que traduz as tensões e paixões que mantiveram unidos o escritor romântico e seu projeto nacionalista e o crítico e escritor realista, autor de Dom Casmurro, que já se afigurava "moderno".

Interessantemente, o livro é aberto com o capítulo "Memórias Póstumas" que, em vez de fornecer dados passados, aponta para marcas futuras que a obra alencariana imprimiu na literatura e cultura brasileiras, e é finalizado com o capítulo "Memórias Prósperas" que, mais que pretender um ludismo fonomorfo-semântico, resgata $\mathrm{O}$ passado/presente criado por Alencar. Evidencia-se o jogo que tão bem o romancista cearence soube jogar: o da memória transfigurada e articulada miticamente para um agora eterno, sempre o mesmo e outro sempre, em que a nação brasileira se tem encontrado e confrontado com a nação colonizadora.

Piguara: Alencar e a invenção do Brasil é uma obra multihistórica, pois agencia a História brasileira, codificando-lhe fatos e personagens, convoca a história literária, pois surpreende o panorama cultural do século
XIX, adota procedimentos da história social e dialética, pois trabalha as contradições entre as forças que dinamizaram o século, utiliza práticas da história das mentalidades, pois recria a atmosfera que circunscreveu a obra alencariana, graças a uma série de micro-histórias, numa bem articulada e conseguida trama. Assim a obra ilumina a demanda da identidade nacional, desnudando o jogo retórico e expressivo em torno da memória e do esquecimento, "tão comum na apreensão da História pelos países colonizados, nomeadamente pelos países latino-americanos". Pensando o Brasil a partir de sua condição de jovem nação, cultural e economicamente periférica, que almeja inserir-se entre as ditas nações civilizadas, o discurso de José de Alencar, renovado pelo livro de Elvya, pressupõe "compensações sócioculturais ambíguas, e de frágeis superações ideológicas do malestar inerente à civilização". Tal é o "paradoxo necessário" de uma construção discursiva oscilante entre os valores locais e a busca da civilização vinda de alhures, cicatriz que profundamente marca a cultura brasileira. 
Piguara: Alencar e a inven- o sustenta, o livro é escrito com ção do Brasil é livro para ler, o saber-sabor que Alencar prerefletir e recomendar. Veio para tendera conferir às suas obras, figurar entre os mais fecundos quando aludira à língua do de quantos a crítica brasileira "povo que chupa o caju, a manproduziu, pois além das quali- ga, o cambucá e a jabuticaba”, dades provenientes de séria porquanto da escrita de Elvya investigação, além da novidade Ribeiro Pereira escorre muito na abordagem do objeto de saber com sabor da fruta madura estudo, além da discussão inte- que deixa na língua o desejo de ligente da bibliografia crítica que quero mais. 